\title{
Cost-effective screening and isolation of xylano-cellulolytic positive microbes from termite gut and termitarium
}

\author{
Libin Mathew Varghese ${ }^{1} \cdot$ Sharad Agrawal $^{1} \cdot$ Divya Sharma $^{1} \cdot$ Rishi Pal Mandhan $^{1} \cdot$ \\ Ritu Mahajan ${ }^{1}$
}

Received: 17 November 2016/Accepted: 19 April 2017/Published online: 31 May 2017

(C) Springer-Verlag Berlin Heidelberg 2017

\begin{abstract}
In this study, screening and isolation of xylanocellulolytic enzymes producing positive microbes from termitarium and termite gut microbiome were done using cost-effective agricultural wastes. The enrichment of xylano-cellulolytic microbes was done in three steps using wheat bran and waste paper. The qualitative screening of xylanase and cellulase producing micro-organisms was done on nutrient agar plates containing wheat bran and waste paper, respectively. Xylanase and cellulase positive colonies were analysed by observing the zone of substrate (wheat bran and waste paper) hydrolysis around the colonies. A total of 30 bacterial isolates were obtained from termite gut and termitarium, respectively. Xylan and cellulose degrading potential of the positive isolates was also quantitatively estimated using agro-wastes-based medium. All the bacterial isolates displayed cellulase and xylanase activities in the range of $0.45-6.80$ and $51-380 \mathrm{IU} / \mathrm{ml}$, respectively. This is the first report mentioning the isolation of xylano-cellulolytic microbes from termite gut and termitarium using very simple cost-effective methodology.
\end{abstract}

Keywords Termite $\cdot$ Termitarium $\cdot$ Xylanase $\cdot$ Cellulase $\cdot$ Wheat bran . Waste paper

Rishi Pal Mandhan and Ritu Mahajan contributed equally to this work.

Rishi Pal Mandhan

kukdbt@gmail.com

1 Department of Biotechnology, Kurukshetra University, Kurukshetra 136119, India

\section{Introduction}

Lignocellulose is the major renewable organic biomass and cheaper source of energy present on the earth (Lynd et al. 2008). The major composition of lignocellulose consists of cellulose, hemicellulose and lignin. The hydrolysis of these lignocellulosic materials to their respective monosaccharides is the major problem and, thus, the high cost of hydrolysis makes the economics of utilizing this abundant source of energy currently unattractive (Putro et al. 2016). Also traditional methods used for degradation of lignocellulose generate toxic chemicals, which can be either replaced by enzymatic methods or can be used in combination with enzymes so as to reduce the environmental pollution. Microbial enzymes which are used in industrial processes are highly efficient and cause less pollution (Desai and Iyer 2016; Kaur et al. 2016).

Microbes present in the wood consuming organisms such as termites, wood borers, beetles, etc. are a potential source of enzymes that help in degrading the lignocellulose (Warnecke and Luginbühl 2007). The symbiotic microbes present in the termite gut are known to produce cellulase and xylanase (Tarayre et al. 2014). The xylano-cellulolytic enzymes are used in many industries like paper, animal feed, biofuel and food (Chutani and Sharma 2016; Pandey et al. 2016; Patel et al. 2016; Tirado-González et al. 2016). There are only few reports of their combined production, till date. The use of purified substrates like xylan (Bastien et al. 2013; Kamsani et al. 2016) and cellulose (Bashir et al. 2013) has been done by many workers for qualitative estimation of enzyme activity during screening of xylanase and cellulase producing microbes from termite gut microbiome and has been found to be very expensive. Kaur et al. (2011) have replaced the use of highly expensive substrates by agricultural wastes for screening purposes. In view of 
various industrial applications of cellulase and xylanase enzymes in combination, the present study was aimed at screening and isolation of potential xylano-cellulolytic enzymes producing microbes from termite gut and termitarium using agro-wastes.

\section{Materials and methods}

\section{Sample collection and other chemicals}

Soil samples from termitarium and wood feeding higher termites were collected from Kurukshetra University Campus, Kurukshetra, Haryana, India. Birchwood xylan and carboxy methyl cellulose (CMC) was purchased from Sigma-Aldrich. All other chemicals used were of highpurity grade. Agro-residues such as wheat bran and waste paper were purchased from the local market.

\section{Enrichment}

The guts of 30 worker termites were removed using sterile forceps and were homogenized in a sterile pestle-mortar using $50 \mathrm{ml}$ deionised water to form gut suspension. One gram of termitarium soil was also mixed with $50 \mathrm{ml}$ deionised sterile water in a separate conical flask. After that, both suspensions were centrifuged at $5000 \mathrm{rpm}$ for 5 min. For obtaining the xylano-cellulolytic microbes, the supernatants obtained after centrifugation were enriched separately according to the protocol described by Singh et al. (2015), with minor modifications. To $2 \mathrm{ml}$ of both clear suspensions, $20 \mathrm{ml}$ of sterile deionised water containing $2 \%$ wheat bran $(\mathrm{pH} 8.5)$ was added in $100 \mathrm{ml}$ Erlenmeyer flasks and kept on a shaker at $37{ }^{\circ} \mathrm{C}$ for $48 \mathrm{~h}$ for enrichment of xylanolytic microbes. Then, $2 \mathrm{ml}$ of enriched inoculum obtained from both the above flasks was transferred to another $100 \mathrm{ml}$ Erlenmeyer flask separately containing $2 \%$ waste paper in $20 \mathrm{ml}$ sterile deionised water, $\mathrm{pH} 8.5$ in order to enrich cellulolytic microbes. The medium was then incubated for $48 \mathrm{~h}$ at $37^{\circ} \mathrm{C}$. In the final step of enrichment, $2 \mathrm{ml}$ of enriched inoculum from both the flasks was again transferred to another $100 \mathrm{ml}$ Erlenmeyer flask containing $2 \%$ waste paper and $2 \%$ wheat bran in $20 \mathrm{ml}$ sterile deionised water, $\mathrm{pH} 8.5$ to further enrich xylano-cellulolytic microbes and incubated in same conditions as mentioned above. These enriched inocula were used for further qualitative screening of xylano-cellulolytic micro-organisms.

\section{Qualitative screening of xylano-cellulolytic microbes}

In the first step, $50 \mu \mathrm{l}$ of cell suspension obtained above from termite gut and termitarium was taken and spread onto nutrient agar plates containing $0.5 \%$ peptone, $0.3 \%$ beef extract, $1.5 \%$ agar, $1 \%$ wheat bran and $1 \%$ waste paper, $\mathrm{pH} 8.5$, separately, for isolation of xylano-cellulolytic microbes. The plates were incubated at $37^{\circ} \mathrm{C}$ for $48 \mathrm{~h}$. The morphologically different and well grown colonies were spotted again on to another nutrient agar plate containing wheat bran and waste paper. Then replica plates were made and incubated at the same conditions as mentioned above. After incubation, replica culture plates were flooded with $0.5 \%$ Congo red solution for $15 \mathrm{~min}$ and were destained with $1 \mathrm{M} \mathrm{NaCl}$ for $15 \mathrm{~min}$. Cellulase and xylanase producing colonies were analysed by evaluating the zone of substrate hydrolysis around the colonies as per method given by Gessesse and Gashe (1997). The xylanocellulolytic positive colonies were also spotted on $1 \%$ carboxy methyl cellulose and $0.25 \%$ xylan containing nutrient agar plates.

In the second step, the colonies which gave zone of substrate hydrolysis in the above step were further spotted onto nutrient agar plates with $0.5 \%$ peptone, $0.3 \%$ beef extract, $1.5 \%$ agar and $1 \%$ waste paper, $\mathrm{pH}$ 8.5. The plates were incubated at $37{ }^{\circ} \mathrm{C}$ for $48 \mathrm{~h}$. After that, replica plates were made and incubated at the same conditions as mentioned above and then treated with Congo red for zone analysis. The cellulase producing colonies were selected by evaluating the zone of substrate hydrolysis. The cellulolytic positive colonies were also spotted on $1 \%$ carboxy methyl cellulose containing nutrient agar plates.

In the final step, the nutrient agar plates containing $0.5 \%$ peptone, $0.3 \%$ beef extract, $1.5 \%$ agar and $1 \%$ wheat bran, pH 8.5 were spotted with colonies, which gave positive results in the second screening step. The plates were incubated at $37{ }^{\circ} \mathrm{C}$ for $48 \mathrm{~h}$. After that, replica plates were made and incubated at the same conditions as given above and treated with Congo red for zone analysis. The xylanase producing colonies were selected by evaluating the zone of substrate hydrolysis. The xylanolytic positive colonies were also spotted on $0.25 \%$ xylan containing nutrient agar plates.

\section{Quantitative screening of xylano-cellulolytic microbes}

Enzyme production was done in $100 \mathrm{ml}$ Erlenmeyer flasks with $20 \mathrm{ml}$ basal media containing $0.5 \%$ peptone, $0.3 \%$ yeast extract, $1 \%$ wheat bran and $1 \%$ waste paper, $\mathrm{pH} 8.5$ under submerged fermentation conditions. The flasks were inoculated with $2 \%$ of $24 \mathrm{~h}$ old inoculum and were incubated in a shaker incubator at $200 \mathrm{rpm}, 37^{\circ} \mathrm{C}$ for $48 \mathrm{~h}$. The crude extracellular enzymes preparation was separated by centrifuging at $10,000 \mathrm{rpm}$ for $10 \mathrm{~min}$ and the clear supernatant was used as a source of enzymes for further use. 
Fig. 1 Zone of substrate hydrolysis shown on, a waste paper plus wheat bran, b xylan plus carboxy methyl cellulose; c waste paper, $\mathbf{d}$ carboxy methyl cellulose; e wheat bran, f xylan

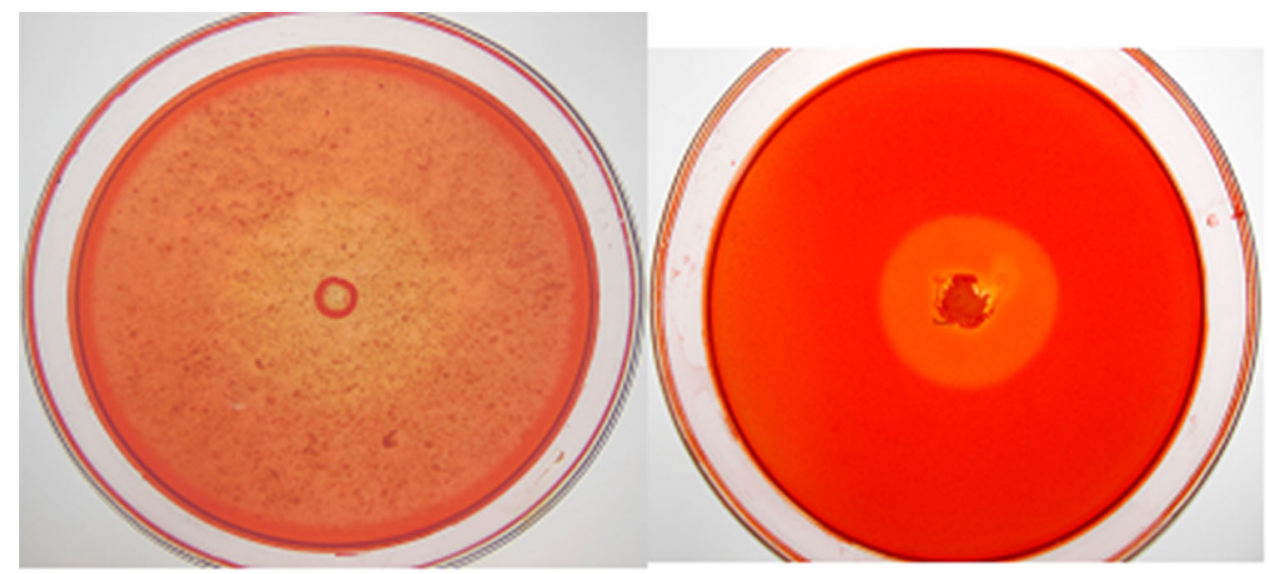

a

b

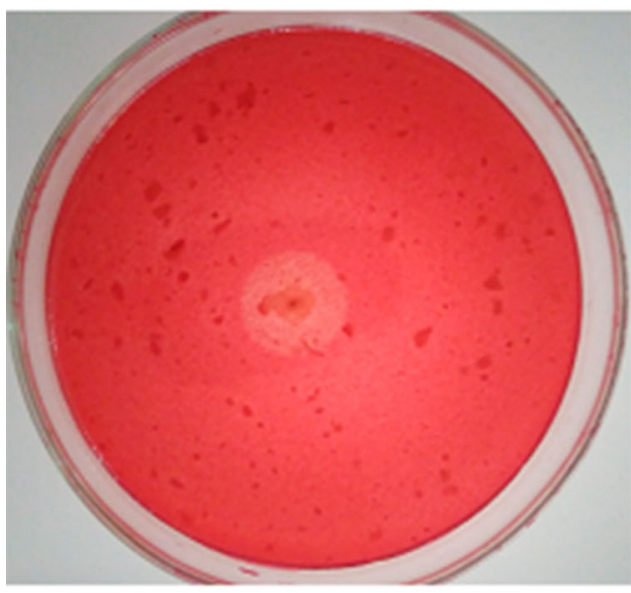

C

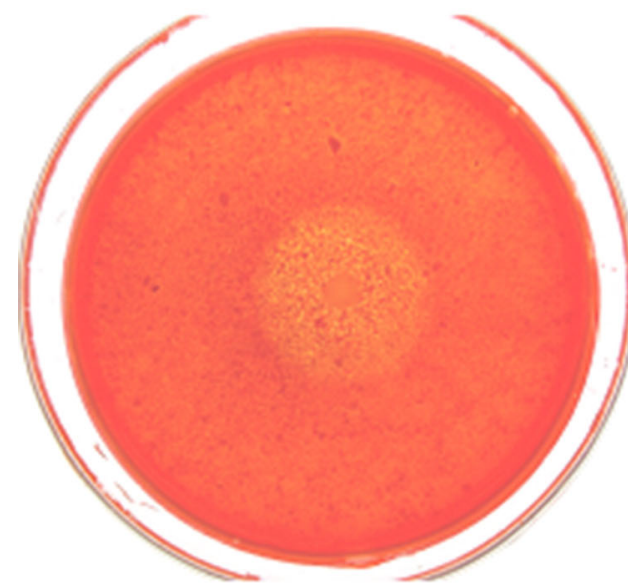

e

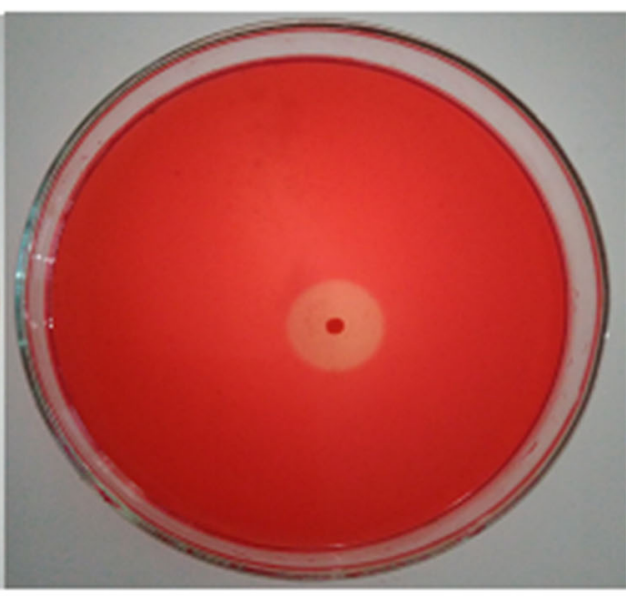

d

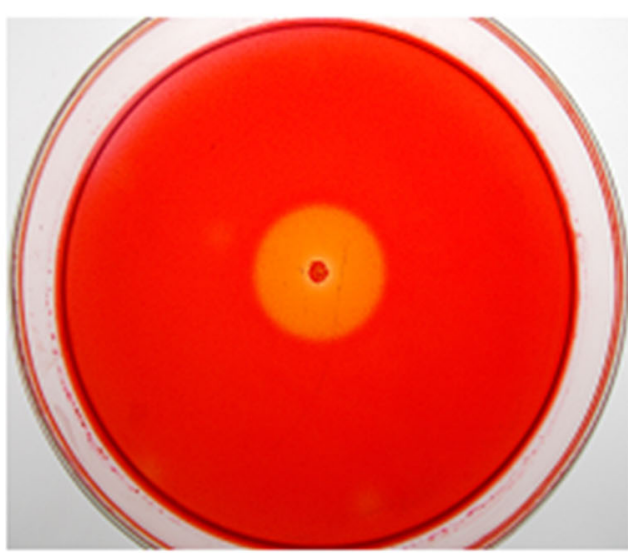

f
Birchwood xylan $1 \%$ and carboxy methyl cellulose $1 \%$ were used for the estimation of xylanase and cellulase activity, respectively. Enzyme assays were carried out using $490 \mu \mathrm{l}$ of respective substrate, prepared in glycine$\mathrm{NaOH}$ buffer, $\mathrm{pH} 8.5$ and $10 \mu \mathrm{l}$ of appropriately diluted enzyme was added. The reaction mixture was incubated at $55^{\circ} \mathrm{C}$ for $10 \mathrm{~min}$ and cooled. The enzymes activity was determined by measuring the amount of reducing sugars liberated after enzyme substrate reaction using 3, 5-dinitrosalicylic acid reagent (Miller 1959). One unit of xylanase and cellulase activity is defined as the amount of enzyme that catalyzes the release of $1 \mu \mathrm{mol}$ of xylose and glucose, respectively, per minute under the specified assay conditions. 
Table 1 Qualitative and quantitative analysis of xylanase and cellulase enzymes from termite gut

\begin{tabular}{|c|c|c|c|c|c|c|c|c|}
\hline \multirow[t]{3}{*}{ Isolates } & \multicolumn{6}{|c|}{ Qualitative analysis } & \multirow{2}{*}{\multicolumn{2}{|c|}{$\frac{\text { Quantitative analysis }}{\text { Enzyme activity }(\mathrm{IU} / \mathrm{ml})^{\mathrm{a}}}$}} \\
\hline & \multicolumn{6}{|c|}{ Diameter $(\mathrm{mm})$ of zone of substrate hydrolysis on agricultural wastes and commercial substrates } & & \\
\hline & Waste paper & Wheat bran & $\begin{array}{l}\text { Wheat bran and } \\
\text { waste paper }\end{array}$ & Cellulose & Xylan & $\begin{array}{l}\text { Xylan and } \\
\text { cellulose }\end{array}$ & Cellulase & Xylanase \\
\hline 1 & $21 \pm 1$ & $33 \pm 1$ & $39 \pm 1$ & $22 \pm 1$ & $34 \pm 1$ & $40 \pm 1$ & $3.8 \pm 0.5$ & $250 \pm 5$ \\
\hline 2 & $17 \pm 1$ & $30 \pm 1$ & $38 \pm 2$ & $17 \pm 1$ & $32 \pm 1$ & $36 \pm 1$ & $2.3 \pm 1$ & $180 \pm 1$ \\
\hline 3 & $21 \pm 1$ & $19 \pm 1$ & $32 \pm 1$ & $21 \pm 1$ & $20 \pm 1$ & $33 \pm 1$ & $3.6 \pm 0.25$ & $119 \pm 4$ \\
\hline 4 & $9 \pm 1$ & $18 \pm 1$ & $21 \pm 1$ & $9 \pm 1$ & $18 \pm 1$ & $21 \pm 1$ & $0.7 \pm 0.2$ & $88 \pm 1$ \\
\hline 5 & $19 \pm 1$ & $30 \pm 1$ & $38 \pm 1$ & $18 \pm 1$ & $30 \pm 1$ & $38 \pm 2$ & $3.1 \pm 0.75$ & $178 \pm 1.5$ \\
\hline 6 & $15 \pm 2$ & $15 \pm 1$ & $25 \pm 1$ & $16 \pm 2$ & $15 \pm 1$ & $26 \pm 1$ & $1.8 \pm 0.5$ & $76 \pm 0.75$ \\
\hline 7 & $18 \pm 1$ & $28 \pm 1$ & $38 \pm 1$ & $18 \pm 1$ & $28 \pm 1$ & $37 \pm 2$ & $2.9 \pm 0.5$ & $150 \pm 0.6$ \\
\hline 8 & $24 \pm 1$ & $32 \pm 2$ & $40 \pm 1$ & $24 \pm 1$ & $32 \pm 3$ & $39 \pm 1$ & $4.4 \pm 1$ & $210 \pm 1$ \\
\hline 9 & $21 \pm 1$ & $29 \pm 1$ & $37 \pm 3$ & $23 \pm 1$ & $30 \pm 1$ & $38 \pm 2$ & $3.7 \pm 1$ & $165 \pm 1.5$ \\
\hline 10 & $25 \pm 3$ & $33 \pm 1$ & $44 \pm 1$ & $25 \pm 2$ & $31 \pm 2$ & $44 \pm 1$ & $4.8 \pm 1$ & $254 \pm 1$ \\
\hline 11 & $17 \pm 1$ & $18 \pm 1$ & $28 \pm 1$ & $18 \pm 1$ & $19 \pm 1$ & $28 \pm 1$ & $2.5 \pm 1$ & $51 \pm 0.5$ \\
\hline 12 & $20 \pm 1$ & $28 \pm 3$ & $37 \pm 1$ & $20 \pm 1$ & $30 \pm 1$ & $38 \pm 1$ & $3.5 \pm 0.75$ & $145 \pm 1$ \\
\hline 13 & $19 \pm 1$ & $28 \pm 1$ & $36 \pm 1$ & $19 \pm 1$ & $28 \pm 1$ & $38 \pm 1$ & $3.2 \pm 0.25$ & $160 \pm 0.5$ \\
\hline 14 & $27 \pm 1$ & $35 \pm 2$ & $45 \pm 1$ & $28 \pm 1$ & $34 \pm 3$ & $46 \pm 1$ & $5.3 \pm 1$ & $318 \pm 1.4$ \\
\hline 15 & $18 \pm 1$ & $28 \pm 1$ & $39 \pm 1$ & $18 \pm 1$ & $27 \pm 1$ & $37 \pm 1$ & $2.8 \pm 0.2$ & $143 \pm 1.4$ \\
\hline 16 & $20 \pm 1$ & $32 \pm 1$ & $39 \pm 1$ & $20 \pm 1$ & $33 \pm 1$ & $38 \pm 1$ & $3.4 \pm 0.2$ & $200 \pm 2$ \\
\hline 17 & $25 \pm 2$ & $32 \pm 1$ & $40 \pm 1$ & $26 \pm 2$ & $31 \pm 1$ & $42 \pm 1$ & $4.8 \pm 0.8$ & $198 \pm 3$ \\
\hline 18 & $24 \pm 1$ & $29 \pm 1$ & $39 \pm 1$ & $23 \pm 1$ & $29 \pm 1$ & $38 \pm 1$ & $4.3 \pm 1$ & $254 \pm 1$ \\
\hline 19 & $19 \pm 1$ & $30 \pm 1$ & $39 \pm 1$ & $19 \pm 1$ & $31 \pm 1$ & $40 \pm 1$ & $3.0 \pm 0.45$ & $175 \pm 1$ \\
\hline 20 & $25 \pm 1$ & $34 \pm 1$ & $40 \pm 2$ & $24 \pm 1$ & $36 \pm 1$ & $39 \pm 2$ & $4.6 \pm 0.25$ & $280 \pm 2$ \\
\hline 21 & $32 \pm 1$ & $36 \pm 1$ & $45 \pm 1$ & $32 \pm 1$ & $38 \pm 1$ & $47 \pm 1$ & $6.8 \pm 0.5$ & $360 \pm 0.6$ \\
\hline 22 & $21 \pm 1$ & $19 \pm 1$ & $32 \pm 1$ & $21 \pm 1$ & $20 \pm 1$ & $33 \pm 1$ & $3.8 \pm 0.2$ & $102 \pm 2$ \\
\hline 23 & $18 \pm 1$ & $16 \pm 1$ & $29 \pm 1$ & $17 \pm 1$ & $17 \pm 2$ & $31 \pm 1$ & $2.7 \pm 0.3$ & $82 \pm 1$ \\
\hline 24 & $17 \pm 1$ & $30 \pm 2$ & $38 \pm 1$ & $17 \pm 1$ & $32 \pm 1$ & $36 \pm 1$ & $2.1 \pm 0.45$ & $174 \pm 0.5$ \\
\hline 25 & $21 \pm 1$ & $19 \pm 1$ & $32 \pm 1$ & $21 \pm 1$ & $20 \pm 1$ & $33 \pm 1$ & $3.2 \pm 0.01$ & $123 \pm 2$ \\
\hline 26 & $7 \pm 1$ & $22 \pm 1$ & $23 \pm 1$ & $7 \pm 1$ & $22 \pm 2$ & $22 \pm 1$ & $0.5 \pm 0.01$ & $100 \pm 1$ \\
\hline 27 & $27 \pm 1$ & $35 \pm 1$ & $45 \pm 1$ & $27 \pm 1$ & $36 \pm 1$ & $45 \pm 1$ & $5.27 \pm 0.6$ & $301 \pm 0.75$ \\
\hline 28 & $21 \pm 1$ & $33 \pm 1$ & $41 \pm 2$ & $22 \pm 1$ & $34 \pm 1$ & $41 \pm 1$ & $3.87 \pm 1$ & $251 \pm 0.8$ \\
\hline 29 & $9 \pm 1$ & $18 \pm 1$ & $21 \pm 1$ & $9 \pm 1$ & $18 \pm 1$ & $21 \pm 1$ & $0.9 \pm 0.4$ & $99 \pm 1$ \\
\hline 30 & $17 \pm 1$ & $15 \pm 1$ & $26 \pm 1$ & $18 \pm 1$ & $16 \pm 1$ & $26 \pm 1$ & $2.43 \pm 0.8$ & $57 \pm 0.6$ \\
\hline
\end{tabular}

Results presented are the mean of three independent experiments with standard deviation values

${ }^{a}$ Under unoptimized conditions

\section{Results and discussion}

Evidences are available in the literature for the presence of micro-organisms in the termite gut and termitarium that help in lignocellulose degradation (Brune 2014; Manjula et al. 2014). The complex lignocellulose polymers within wood are broken down into simple sugars by fermenting bacteria in the termite's gut, using lignocellulolytic enzymes which can be used for many industrially important processes. Moreover, the potential for the production of biofuel from the fermentation of the simple sugars obtained from lignocellulose decomposition in this way is tremendous.

Keeping this in mind, this study was carried out to screen and isolate industrially important xylano-cellulolytic microbes from termite gut and termitarium. A total of 30 bacterial isolates were isolated from termite gut and termitarium, respectively. In this paper, we have used multiple enrichment and screening steps in order to get xylano-cellulolytic enzymes producing microbes from termitarium and termite gut. Cost-effective agro-wastes were used for screening and enrichment purposes as described 
Table 2 Qualitative and quantitative analysis of xylanase and cellulase enzymes from termitarium

\begin{tabular}{|c|c|c|c|c|c|c|c|c|}
\hline \multirow[t]{3}{*}{ Isolates } & \multicolumn{6}{|c|}{ Qualitative analysis } & \multirow{2}{*}{\multicolumn{2}{|c|}{$\frac{\text { Quantitative analysis }}{\text { Enzyme activity }(\mathrm{IU} / \mathrm{ml})^{\mathrm{a}}}$}} \\
\hline & \multicolumn{6}{|c|}{ Diameter $(\mathrm{mm})$ of zone of substrate hydrolysis on agricultural wastes and commercial substrates } & & \\
\hline & Waste paper & Wheat bran & $\begin{array}{l}\text { Wheat bran and } \\
\text { waste paper }\end{array}$ & Cellulose & Xylan & $\begin{array}{l}\text { Xylan and } \\
\text { cellulose }\end{array}$ & Cellulase & Xylanase \\
\hline 1 & $17 \pm 1$ & $19 \pm 1$ & $28 \pm 1$ & $17 \pm 1$ & $18 \pm 1$ & $29 \pm 1$ & $2.47 \pm 0.7$ & $101 \pm 1$ \\
\hline 2 & $15 \pm 1$ & $15 \pm 1$ & $25 \pm 1$ & $16 \pm 1$ & $15 \pm 1$ & $26 \pm 1$ & $1.83 \pm 1$ & $55 \pm 2$ \\
\hline 3 & $21 \pm 1$ & $31 \pm 1$ & $37 \pm 3$ & $22 \pm 1$ & $32 \pm 1$ & $36 \pm 2$ & $3.76 \pm 1$ & $186 \pm 1$ \\
\hline 4 & $7 \pm 1$ & $34 \pm 1$ & $32 \pm 1$ & $7 \pm 1$ & $34 \pm 1$ & $32 \pm 1$ & $0.57 \pm 0.2$ & $287 \pm 0.5$ \\
\hline 5 & $25 \pm 1$ & $30 \pm 2$ & $39 \pm 1$ & $24 \pm 1$ & $29 \pm 2$ & $39 \pm 1$ & $4.8 \pm 1$ & $179 \pm 1.5$ \\
\hline 6 & $33 \pm 1$ & $38 \pm 1$ & $45 \pm 1$ & $34 \pm 1$ & $40 \pm 1$ & $47 \pm 1$ & $6.02 \pm 0.7$ & $380 \pm 3$ \\
\hline 7 & $13 \pm 1$ & $34 \pm 1$ & $37 \pm 1$ & $13 \pm 1$ & $33 \pm 1$ & $38 \pm 1$ & $1.23 \pm 1$ & $274 \pm 0.4$ \\
\hline 8 & $9 \pm 1$ & $18 \pm 1$ & $21 \pm 1$ & $9 \pm 1$ & $18 \pm 1$ & $21 \pm 1$ & $0.75 \pm 0.9$ & $84 \pm 1.6$ \\
\hline 9 & $18 \pm 1$ & $16 \pm 1$ & $29 \pm 1$ & $17 \pm 1$ & $17 \pm 1$ & $31 \pm 1$ & $2.86 \pm 1$ & $67 \pm 2$ \\
\hline 10 & $20 \pm 2$ & $22 \pm 1$ & $36 \pm 1$ & $21 \pm 1$ & $23 \pm 1$ & $37 \pm 1$ & $3.50 \pm 0.5$ & $115 \pm 1$ \\
\hline 11 & $23 \pm 1$ & $32 \pm 1$ & $40 \pm 1$ & $24 \pm 1$ & $33 \pm 1$ & $40 \pm 2$ & $4.21 \pm 1$ & $201 \pm 0.7$ \\
\hline 12 & $27 \pm 1$ & $38 \pm 1$ & $47 \pm 1$ & $26 \pm 1$ & $39 \pm 1$ & $46 \pm 1$ & $5.54 \pm 1$ & $370 \pm 1.8$ \\
\hline 13 & $17 \pm 1$ & $33 \pm 1$ & $40 \pm 1$ & $17 \pm 1$ & $33 \pm 1$ & $40 \pm 1$ & $2.6 \pm 0.2$ & $223 \pm 2.5$ \\
\hline 14 & $23 \pm 1$ & $35 \pm 1$ & $43 \pm 1$ & $23 \pm 2$ & $36 \pm 1$ & $42 \pm 1$ & $4.5 \pm 0.5$ & $320 \pm 1$ \\
\hline 15 & $29 \pm 1$ & $32 \pm 1$ & $45 \pm 1$ & $30 \pm 1$ & $32 \pm 1$ & $46 \pm 1$ & $3.6 \pm 1$ & $245 \pm 1.2$ \\
\hline 16 & $24 \pm 1$ & $29 \pm 2$ & $39 \pm 1$ & $23 \pm 1$ & $28 \pm 2$ & $39 \pm 1$ & $4.57 \pm 0.4$ & $157 \pm 0.5$ \\
\hline 17 & $27 \pm 1$ & $35 \pm 1$ & $45 \pm 1$ & $27 \pm 1$ & $36 \pm 1$ & $45 \pm 1$ & $5.27 \pm 0.6$ & $301 \pm 0.75$ \\
\hline 18 & $21 \pm 1$ & $33 \pm 1$ & $41 \pm 2$ & $22 \pm 1$ & $34 \pm 1$ & $41 \pm 1$ & $3.87 \pm 1$ & $251 \pm 0.8$ \\
\hline 19 & $10 \pm 1$ & $22 \pm 1$ & $25 \pm 1$ & $10 \pm 1$ & $22 \pm 1$ & $25 \pm 1$ & $0.83 \pm 0.3$ & $103 \pm 5$ \\
\hline 20 & $17 \pm 1$ & $15 \pm 1$ & $26 \pm 1$ & $18 \pm 1$ & $16 \pm 1$ & $26 \pm 1$ & $2.43 \pm 0.8$ & $57 \pm 0.6$ \\
\hline 21 & $20 \pm 1$ & $32 \pm 1$ & $39 \pm 1$ & $20 \pm 1$ & $32 \pm 1$ & $40 \pm 1$ & $3.5 \pm 1$ & $216 \pm 0.2$ \\
\hline 22 & $25 \pm 1$ & $31 \pm 1$ & $40 \pm 1$ & $25 \pm 2$ & $30 \pm 1$ & $39 \pm 1$ & $4.7 \pm 0.5$ & $183 \pm 1$ \\
\hline 23 & $20 \pm 1$ & $28 \pm 1$ & $37 \pm 1$ & $21 \pm 1$ & $29 \pm 1$ & $38 \pm 1$ & $3.45 \pm 0.75$ & $145 \pm 3$ \\
\hline 24 & $19 \pm 1$ & $28 \pm 1$ & $37 \pm 1$ & $19 \pm 1$ & $28 \pm 1$ & $38 \pm 1$ & $3.17 \pm 1$ & $167 \pm 0.5$ \\
\hline 25 & $6 \pm 1$ & $21 \pm 1$ & $23 \pm 1$ & $6 \pm 1$ & $22 \pm 1$ & $23 \pm 1$ & $0.45 \pm 0.2$ & $83 \pm 0.9$ \\
\hline 26 & $25 \pm 1$ & $33 \pm 1$ & $40 \pm 1$ & $24 \pm 1$ & $34 \pm 1$ & $40 \pm 1$ & $4.75 \pm 0.8$ & $258 \pm 1$ \\
\hline 27 & $18 \pm 1$ & $22 \pm 1$ & $35 \pm 1$ & $18 \pm 1$ & $23 \pm 1$ & $35 \pm 1$ & $2.73 \pm 0.2$ & $115 \pm 0.8$ \\
\hline 28 & $27 \pm 1$ & $35 \pm 1$ & $45 \pm 1$ & $29 \pm 1$ & $36 \pm 1$ & $44 \pm 1$ & $5.18 \pm 1$ & $320 \pm 1$ \\
\hline 29 & $13 \pm 1$ & $21 \pm 1$ & $32 \pm 1$ & $13 \pm 1$ & $22 \pm 1$ & $28 \pm 1$ & $1.10 \pm 1$ & $160 \pm 1$ \\
\hline 30 & $17 \pm 2$ & $32 \pm 1$ & $37 \pm 1$ & $17 \pm 1$ & $33 \pm 1$ & $38 \pm 1$ & $2.47 \pm 0.7$ & $208 \pm 0.2$ \\
\hline
\end{tabular}

Results presented are the mean of three independent experiments with standard deviation values

${ }^{a}$ Under unoptimized conditions

by Singh et al. (2015), as purified substrates like xylan and cellulose are expensive. In the first screening step, nutrient agar/waste paper/wheat bran plates were stained with Congo red stain. Clear zones around the colonies were observed due to substrate hydrolysis, which indicated that these colonies produced either cellulase or xylanase or both of them together. The zones observed on wheat bran and waste paper containing nutrient agar plates (Fig. 1a) and on xylan and carboxy methyl cellulose-nutrient agar plates (Fig. 1b) were nearly the same in diameter.

In the second step, the positive colonies isolated from first screening step, were grown on nutrient agar medium containing waste paper. The colonies which formed clear zone around them after Congo red staining indicated that these colonies are producing cellulase, as waste paper contains cellulose. The results were also evaluated on commercial cellulose containing nutrient agar plates. Isolates which showed zone of substrate hydrolysis on waste paper-nutrient agar plates also showed comparable zones on carboxy methyl cellulose-nutrient agar plates (Fig. 1c, d). Bashir et al. (2013) and Behera et al. (2014) used carboxy methyl cellulose to qualitatively screen the cellulase producing colonies from termite gut and mangrove soils of Mahanadi river delta, respectively. In the final step, 
positive isolates from second step were spotted onto nutrient agar/wheat bran medium. The screening of the xylanolytic bacterial isolates was performed using wheat bran, as it contains arabinoxylan. The formation of zone of substrate hydrolysis around colonies showed that, these isolates also produced xylanase (Fig. 1e). These positive isolates were also spotted on commercial xylan-nutrient agar plates which were then analysed for zone of substrate hydrolysis (Fig. 1f). Pure xylan has been added in the agar medium for qualitative detection of xylanolytic micro-organisms by many researchers. Some workers have also used purified xylan to qualitatively screen xylanase enzyme from termite gut (Bastien et al. 2013; Kamsani et al. 2016).

Upon further quantitative analysis of cellulose and xylan degrading enzymes, all 30 bacterial isolates isolated from termite gut displayed cellulase (CMCase) and xylanase activity in the range of $0.5-6.8$ and $51-360 \mathrm{IU} / \mathrm{ml}$, respectively, and all 30 bacterial isolates isolated from termitarium displayed cellulase (CMCase) and xylanase activity in the range of $0.45-6.02$ and $55-380 \mathrm{IU} / \mathrm{ml}$, respectively. Tables 1 and 2 show qualitative and quantitative analysis of xylanase and cellulase enzymes from termite gut and termitarium, respectively, using agricultural wastes and commercial substrates. The best xylanocellulolytic bacterial isolate no. 21 isolated from termite gut produced xylanase and cellulase activities of 360 and $6.8 \mathrm{IU} / \mathrm{ml}$, respectively; and bacterial isolate no. 6 isolated from termitarium produced xylanase and cellulase activities of 380 and $6.02 \mathrm{IU} / \mathrm{ml}$, respectively.

\section{Conclusion}

Termites are considered as voracious pest on wood. Termite gut and termitarium have diverse microbial flora, which are able to digest the main components of lignocellulosic materials and this is to the fact that they have enzymatic machinery to degrade lignocelluloses. This study shows a very simple methodology for isolating xylano-cellulolytic micro-organisms living in the termite gut and termitarium using agro-wastes. In this study, this approach has been used for termites; this methodology can also be applied on other wood feeding organisms like wood borers, beetles, etc. for isolating commercially important biocatalysts. Termites offer huge prospects for isolation of micro-organisms producing lignocellulose degrading enzymes. This type of study on termitarium and termite gut microbiome can lead to the discovery of commercially suitable biocatalysts which can be utilized in various industries.

Acknowledgements The authors gratefully acknowledge the financial support provided by Major Research Project (F. No. 42-223/ 2013), University Grants Commission, New Delhi, India.

\section{Compliance with ethical standards}

Conflict of interest The authors declare that they have no conflict of interest.

\section{References}

Bashir Z, Kondapalli VK, Adlakha N, Sharma A, Raj K, Bhatnagar RK, Chandel G, Yazdani SS (2013) Diversity and functional significance of cellulolytic microbes living in termite, pill-bug and stem-borer guts. Sci Rep 3. doi:10.1038/srep02558

Bastien G, Arnal G, Bozonnet S, Laguerre S, Ferreira F, Fauré R, Henrissat B, Lefèvre F, Robe P, Bouchez O, Noirot C, Dumon C, O'Donohue M (2013) Mining for hemicellulases in the fungusgrowing termite Pseudacanthotermes militaris using functional metagenomics. Biotechnol Biofuels 6(78):1-15

Behera BC, Mishra RR, Singh SK, Dutta SK, Thatoi H (2014) Cellulase from Bacillus licheniformis and Brucella sp. isolated from mangrove soils of Mahanadi river delta, Odisha, India. Biocatal Biotransform 34:44-53

Brune A (2014) Symbiotic digestion of lignocellulose in termite guts. Nat Rev Microbiol 12:168-180

Chutani P, Sharma KK (2016) Concomitant production of xylanases and cellulases from Trichoderma longibrachiatum MDU-6 selected for the deinking of paper waste. Bioprocess Biosyst Eng 39:747-758

Desai DI, Iyer BD (2016) Biodeinking of old newspaper pulp using a cellulase-free xylanase preparation of Aspergillus niger DX-23. Biocatal Agric Biotechnol 5:78-85

Gessesse A, Gashe BA (1997) Production of alkaline xylanase by an alkaliphilic Bacillus sp. isolated from an alkaline soda lake. J Appl Microbiol 83:402-406

Kamsani N, Salleh MM, Yahya A, Chong CS (2016) Production of lignocellulolytic enzymes by microorganisms isolated from Bulbitermes sp. termite gut in solid-state fermentation. Waste Biomass Valoriz 7:357-371

Kaur A, Mahajan R, Singh A, Garg G, Sharma J (2011) A novel and cost effective methodology for qualitative screening of alkalothermophilic cellulase free xylano-pectinolytic microorganisms using agricultural wastes. World J Microbiol Biotechnol 27:459-463

Kaur A, Singh A, Patra AK, Mahajan R (2016) Cost-effective scouring of flax fibers using cellulase-free xylano-pectinolytic synergism from a bacterial isolate. J Clean Prod 131:107-111

Lynd LR, Laser MS, Bransby D, Dale BE, Davison B, Hamilton R, Himmel M, Keller M, McMillan JD, Sheehan J, Wyman CE (2008) How biotech can transform biofuels. Nat Biotechnol 26:169-172

Manjula A, Sathyavathi S, Pushpanathan M, Gunasekaran P, Rajendhran J (2014) Microbial diversity in termite nest. Curr Sci 106:1430-1434

Miller GL (1959) Use of dinitrosalicylic acid reagent for determination of reducing sugars. Anal Chem 31:426-428

Pandey AK, Edgard G, Negi S (2016) Optimization of concomitant production of cellulase and xylanase from Rhizopus oryzae SN5 through EVOP-factorial design technique and application in sorghum stover based bioethanol production. Renew Energy 98:51-56

Patel AK, Singhania RR, Pandey A (2016) Novel enzymatic processes applied to the food industry. Curr Opin Food Sci 7:64-75

Putro JN, Soetaredjo FE, Lin SY, Ju YH, Ismadji S (2016) Pretreatment and conversion of lignocellulose biomass into valuable chemicals. RSC Adv 6:46834-46852 
Singh A, Kaur A, Dua A (2015) Mahajan R (2015) An efficient and improved methodology for the screening of industrially valuable xylano-pectino-cellulolytic microbes. Enzyme Res 725281:1-7

Tarayre C, Brognaux A, Bauwens J, Brasseur C, Mattéotti C, Millet C, Destain J, Vandenbol M, Portetelle D, De Pauw E, Eric H, Francis F, Thonart P (2014) Isolation of amylolytic, xylanolytic, and cellulolytic microorganisms extracted from the gut of the termite Reticulitermes santonensis by means of a micro-aerobic atmosphere. World J Microbiol Biotechnol 30:1655-1660
Tirado-González DN, Jáuregui-Rincón J, Tirado-Estrada GG, Martínez-Hernández PA, Guevara-Lara F, Miranda-Romero LA (2016) Production of cellulases and xylanases by white-rot fungi cultured in corn stover media for ruminant feed applications. Anim Feed Sci Technol 221:147-156

Warnecke F, Luginbühl P (2007) Metagenomic and functional analysis of hindgut microbiota of a wood-feeding higher termite. Nature 450:560-565 